\title{
Informing About the Nocebo Effect Affects Patients' Need for Information About Antidepressants-An Experimental Online Study
}

\begin{abstract}
Yvonne Nestoriuc ${ }^{1,2 \star}$, Yiqi Pan ${ }^{3}$, Timm Kinitz ${ }^{4}$, Ella Weik ${ }^{5}$ and Meike C. Shedden-Mora ${ }^{3,6}$
${ }^{1}$ Clinical Psychology, Helmut-Schmidt-University/University of the Federal Armed Forces Hamburg, Hamburg, Germany, ${ }^{2}$ Systems Neuroscience, University Medical Center Hamburg-Eppendorf, Hamburg, Germany, ${ }^{3}$ Psychosomatic Medicine and Psychotherapy, University Medical Center Hamburg-Eppendorf, Hamburg, Germany, ${ }^{4}$ Neuropsychology, Westerwald Clinic, Waldbreitbach, Germany, ${ }^{5}$ Department of Psychiatry, British Columbia Mental Health and Addictions Research Institute, University of British Columbia, Vancouver, BC, Canada, ${ }^{6}$ Department of Psychology, Medical School Hamburg, Hamburg, Germany
\end{abstract}

Relevance: Understanding patients' informational needs and adapting drug-related information are the prerequisites for a contextualized informed consent. Current information practices might rather harm by inducing nocebo effects.

Objective: To investigate whether informing about the nocebo effect using a short information sheet affects patients' need for information about antidepressants.

Methods: A total of 97 patients taking recently prescribed antidepressants ( $\leq 4$ months intake) were recruited over the internet and randomized to receiving either a one-page written information about the nocebo effect or a control text about the history of antidepressants. After experimental manipulation, informational needs about the side effects and mechanisms of antidepressants were assessed with 3 and 7 items on categorical and 5-point Likert scales. Group differences in informational needs were calculated with Chi-square tests and ANOVAs.

Results: Patients received antidepressants for depression (84.5\%) and/or anxiety disorders (42.3\%). Three participants $(6.0 \%)$ of the nocebo group reported previous knowledge of the nocebo effect. After the experimental manipulation, participants in the nocebo group reported a reduced desire for receiving full side effect information $\left[X_{(4,97)}^{2}=12.714\right.$, Cramer's $\left.V=0.362, p=0.013\right]$ and agreed more frequently to the usefulness of withholding information about possible side effects $\left[X_{(4,97)}^{2}=14.878\right.$, Cramer's $V=0.392, p=0.005]$. Furthermore, they desired more information about the mechanisms of antidepressants $\left(F=6.373, p=0.013\right.$, partial $\left.\eta^{2}=0.063\right)$ and, specifically, non-pharmacological mechanisms, such as the role of positive expectations ( $F=16.857, p<0.001$, partial $\left.\eta^{2}=0.151\right)$.

Conclusions: Learning about the nocebo effect can alter patients' informational needs toward desiring less information about the potential side effects of antidepressants and more information about general mechanisms, such as expectations. The beneficial 
effects of including nocebo information into contextualized informed consent should be studied clinically concerning more functional information-seeking behavior, which may ultimately lead to improved treatment outcomes, such as better adherence and reduced side effect burden.

Keywords: informed consent, antidepressants, nocebo effects, ethics, shared decision making, expectation, adverse (side) effects

\section{INTRODUCTION}

In today's Western healthcare systems, informed consent represents a fundamentally ethical and legal requirement for any medical intervention. It is considered an inherent part of evidence-based practice. However, by providing information about the medications' potential side effects, practitioners may induce nocebo effects and cause harm $(1,2)$. Even reading the package leaflet of any given medication has been shown to increase side effect reporting $(3,4)$. Thus, informing a patient about a treatment provides a direct link to this treatments' efficacy and tolerability. Ethically and clinically, this association has direct implications for informed consent procedures (5).

Nocebo effects may account for $38-100 \%$ of side effects reported in pharmacological trials, including serious adverse events (6). Particularly large placebo and nocebo effects have been documented in antidepressant treatment (7-10). A metaanalysis focusing on adverse event reporting showed that side effects specific to the drug emerge in the placebo groups of antidepressant medication trials, indicating that expectations are powerful enough to bias double-blind randomized trials (8). The role of expectations to predict the outcome of antidepressant treatment is prominent (11), but implications regarding the prevention of potential harm through negative expectations are rare. Clinical and experimental evidence suggests that noceborelated side effects are caused by patients' expectations (1214), prior experiences, and conditioning processes $(15,16)$ as well as misattributions of pre-existing bodily symptoms (17) and social observation (18). Patients with depression might particularly be at risk due to frequent catastrophic thinking and, hence, are more prone to developing negative expectations $(19,20)$. In some patients, fear of side effects can be strong enough to motivate them to discontinue their antidepressant medication (21).

Antidepressant use is common, with an annual average of 1.52 billion daily doses prescribed in Germany (22). In the US, antidepressants are used by $13 \%$ of the country's population, with a continuously increasing trend from 1999 to 2014 (23). Even though patient information procedures are essential to prescribing new drugs, their potential to optimize patients' expectations remains untapped. Among other reasons, prescribing physicians might be unaware of the importance of contextual factors, such as the relevance of side effects information and patients' expectations contributing to side effect burden (24). Common side effects associated with antidepressant treatment include headache, weight gain, dizziness, and dry mouth, as well as adverse effects of long-term antidepressant intake, such as emotional numbing (25).
Providing patients with comprehensive information about their medication is essential in light of patient autonomy. However, informing about side effects might also cause harm (26). To handle this ethical dilemma, promising approaches targeted to reduce expectation-induced side effects while still respecting patient autonomy and truthfulness have been suggested. Experimentally validated strategies include framing side effect information positively $(4,27)$, personalizing informed consent and educating about the medication's mechanism of action (28), and explicitly informing about the nocebo effect itself (29). An important theoretical proposal suggests to contextualize the informed consent by providing medication information in a manner that is personalized to the patient's characteristics, underlying disease, health status, and informational needs (30).

Contextualized informed consent might entail withholding information that may induce harm to patients. Being a theoretically discussed approach among experts, the patient's view regarding this so-called authorized concealment remains unknown. Relevantly, very few individuals are aware of the nocebo effect and thus might not be able to express the need for respective medication information (29).

In this study, we will examine whether patients undergoing antidepressant treatment are open to receiving contextualized medication information, and in specific, what kind of information they wish or wish not to receive. Based on the assumption that knowledge about the nocebo effect might be prerequisite to contextualizing side effect information, we will inform one group of patients about nocebo effects and test whether this will influence patients' informational needs. We assume that patients informed about the nocebo effect express a decreased need for detailed information about side effects and an increased need for information about the nonpharmacological mechanisms of side effect development in comparison with patients who were not informed about the nocebo effect.

\section{METHODS AND PROCEDURES}

\section{Participants}

Participants for this study were recruited via four online depression forums, an advertisement on a local newspaper's website, information sheets distributed in three different hospitals in the Hamburg metropolitan area, and four self-help groups. Inclusion criteria included a minimum age of 18, good knowledge of German, and having started a new antidepressant within the last 4 months. 


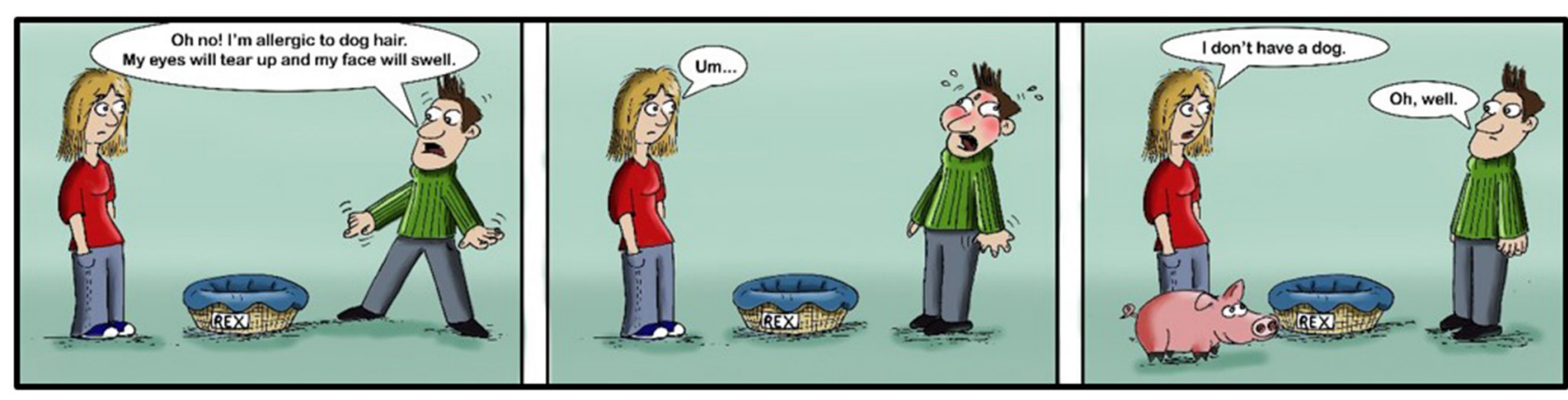

FIGURE 1 | Illustration of nocebo effects in everyday life. ()Timm Kinitz.

\section{Study Design and Procedure}

Ethics approval was obtained from the Psychotherapy Chamber Hamburg, Germany. The survey was assessed via an online link. On the first page, all participants were informed about study procedure and data storage. By checking a box on the website, informed consent was provided by all participants prior to study start. Participants were then asked to provide information on socio-demographic data, illness-related data, and their satisfaction with the received medication information. Then, participants were randomized to receiving either a short information about the nocebo effect or neutral information.

The nocebo information group received a one-page text about the nocebo effect and its mechanisms; the control group received a text of the same length about the history of antidepressants. The nocebo information consisted of three main parts: a comprehensive explanation of the experienced nocebo effect, a distinction of pharmacological and non-pharmacological effects of a drug, and a description of expectations as one possible mechanism of the nocebo effect (31). Within the first paragraph, examples of expectations stemming from prior negative treatment experiences or from learning about the potential side effects from package inserts were given. It was further described that these negative expectations can lead to heightened side effects, that these symptoms are real and not "made up," and that studies have shown that over half of the experienced side effects can be caused by expectations rather than by biomedical factors (17). The second paragraph detailed that medication side effects can be caused via two routes: through pharmacological mechanisms that are specific for the type of antidepressant medication and through nonpharmacological mechanisms, such as patients' expectations. The third paragraph detailed that expectations can trigger biomedical changes within the body; furthermore, that expectations can lead to focused bodily attention, thereby making it likely for a person to attribute normal bodily sensations, such as benign headaches, as a side effect of a given medication. The text was followed by a three-panel comic illustrating the effect (see Figure 1). The control group text did not include information on the efficacy or mechanisms of action of antidepressant treatment. It described the clinical use of antidepressants since the 1950s and the different types of antidepressants that have since been prescribed to patients. A manipulation check was conducted using three single choice questions about the texts' content. Participants were then asked about which medication information they would like to obtain and what degree of side effect disclosure they considered to be useful.

\section{Measures}

\section{Demographic and Medical Characteristics}

The online survey assessed basic socio-demographic data, selfreported diagnosis, type of antidepressant medication, and utilized sources to receive information about their medication. Depression severity was assessed with the German short version of the Center for Epidemiological Studies-Depression (CES-D) scale $(32,33)$. Adherence was assessed via self-report using a prior validated single item ("How many pills have you actually taken during the last week?") (34). Patients who took $80 \%$ or more pills were classified as adherent.

\section{Satisfaction With Information About Medication}

We developed five items to assess the satisfaction with the information about the antidepressant treatment: overall satisfaction, comprehensibility of the information, time and occasion to pose questions to the clinician, feeling sufficiently informed to take part in decision-making about the antidepressant treatment, feeling sufficiently informed to take part in decision-making about side effect treatments, and whether the information was delivered with kindness and respect. Each item is rated on a scale from 1 to 5 (1 "not at all," 2 "rather not," 3 "unsure," 4 "rather satisfied," 5 "very much satisfied"). We dichotomized the items for easier interpretation, with ratings of 4 and 5 grouped as "satisfied." The satisfaction with the consultation time was assessed additionally.

We also used the Satisfaction with Information about Medicines Scale (SIMS) (35). The subscales satisfaction with information on "action and usage of medication" and "potential problems of medications" ranges from 0 to 9 and 0 to 8 , with higher scores indicating a higher degree of satisfaction. A total score is calculated by adding up all items. 


\section{Outcome: Preferred Information Disclosure Disclosure About Risks of Side Effects}

We operationalized the preference for information by addressing two aspects. Patients were asked about their wish to be informed about the side effects and about the mechanisms of antidepressants.

The extent of informational needs about side effects was assessed with three items: (1) "Would you find it beneficial if your practitioner did not inform you about all possible side effects?," rated as "very beneficial," "beneficial, but only with my consent," "undecided," "not very beneficial," or "not at all beneficial"; (2) "How thoroughly would you like your practitioner to inform you about possible side effects?", rated from 1 "not at all" to 5 "very thoroughly"; and (3) "Which side effects would you like to be informed about?", rated as "all side effects," "only the most common ones," "only the most severe ones," "only the personally relevant ones," or "none."

\section{Disclosure About Antidepressant Mechanisms}

Informational needs about antidepressants' mechanisms were measured with seven items on a scale from 1 "fully disagree" to 5 "fully agree." Two items refer to the pharmacological mechanisms of antidepressants, whereas another five items refer to non-pharmacological mechanisms. In specific, patients were asked to indicate whether they would like their practitioner to inform them about the fact (1) "that antidepressants target messenger substances (neurotransmitters) in the brain," (2) "that antidepressants have a pharmacological effect on the body via its biochemical pathways," (3) "that my expectations about the treatment influence the effectiveness of the antidepressant," (4) "that the antidepressant would be less effective if I was not convinced of its benefits," (5) "that antidepressants have a nonpharmacological effect on the body (placebo effect) conveyed by hope for recovery or the attentive care of a physician," (6) "that time itself can contribute to easing my suffering," and (7) "that side effects can develop due to heightened attention to bodily sensations."

\section{Statistical Analyses}

To compare the nocebo information group and the control group, Chi-square tests were conducted for categorical data, and $t$-tests for continuous variables. Welch $t$-tests were conducted if variances were unequal. Analyses were conducted using IBM SPSS 24. All tests were two-tailed with the alpha level set at 0.05.

\section{RESULTS}

\section{Sample Characteristics}

Of 347 participants who started the online questionnaire, 102 participants completed the survey. Participants who could not identify their antidepressant medication (i.e., by checking a box within a comprehensive list of antidepressants) or who reported an intake time of more than 4 months were excluded. After completing the study, participants were excluded if completion time was two standard deviations above mean $(n=2)$, if they did not remember having received medication information from their prescribing physician $(n=2)$, or if they failed all questions
TABLE 1 | Socio-demographic, medical characteristics, and satisfaction with medication information.

\begin{tabular}{|c|c|c|}
\hline & $\begin{array}{l}\text { Nocebo information } \\
\text { group }(n=49) \\
M \pm S D \text { or } \%(n)\end{array}$ & $\begin{array}{l}\text { Control group } \\
(n=48) \\
M \pm S D \text { or \% (n) }\end{array}$ \\
\hline Age & $39.6 \pm 10.0$ & $38.6 \pm 13.7$ \\
\hline Female & $59.2(29)$ & $54.2(56)$ \\
\hline Married/with partner & $40.8(20)$ & $39.6(19)$ \\
\hline 13 or more years of education & $22.4(11)$ & $35.4(17)$ \\
\hline Employed & $51.0(25)$ & $43.8(21)$ \\
\hline \multicolumn{3}{|l|}{ Diagnosis ${ }^{a}$} \\
\hline Depression & $85.7(42)$ & $83.3(40)$ \\
\hline Anxiety disorder & $46.9(23)$ & $37.5(18)$ \\
\hline Bipolar disorder & $6.1(3)$ & $10.4(5)$ \\
\hline Pain disorder & $2.0(1)$ & $10.4(5)$ \\
\hline Obsessive compulsive disorder & $2.0(1)$ & $4.2(2)$ \\
\hline Other & $0.0(0)$ & $4.2(2)$ \\
\hline \multicolumn{3}{|l|}{ Type of antidepressants } \\
\hline Citalopram & $24.5(12)$ & $83.3(13)$ \\
\hline Venlafaxine & $14.3(7)$ & $14.6(7)$ \\
\hline Escitalopram & $14.3(7)$ & $4.2(2)$ \\
\hline Mirtazapine & $8.2(4)$ & $10.4(5)$ \\
\hline Sertraline & $8.2(4)$ & $10.4(5)$ \\
\hline Fluoxetine & $6.1(3)$ & $6.3(3)$ \\
\hline Amitriptyline & $0(0)$ & $8.4(4)$ \\
\hline Opipramol & $4.1(2)$ & $2.1(1)$ \\
\hline Agomelatine & $2.0(1)$ & $4.2(2)$ \\
\hline Other $^{b}$ & $20.4(10)$ & $16.7(8)$ \\
\hline Depression severity (CES-D) & $19.9 \pm 9.6$ & $17.9 \pm 8.67$ \\
\hline Adherent ( $80 \%$ or more pill intake) & $86(42)$ & $81(39)$ \\
\hline \multicolumn{3}{|l|}{ Prescriber } \\
\hline Psychiatrist & $55.1(27)$ & $54.2(26)$ \\
\hline General practitioner & $22.4(11)$ & $10.4(5)$ \\
\hline Practitioner in the clinic & $16.3(8)$ & $14.6(7)$ \\
\hline Neurologist & $6.1(3)$ & $18.8(9)$ \\
\hline Other & $0(0)$ & $2.1(1)$ \\
\hline \multicolumn{3}{|l|}{$\begin{array}{l}\text { Satisfaction with Information } \\
\text { (SIMS) }\end{array}$} \\
\hline Action and usage of medication ${ }^{c}$ & $6.1 \pm 2.7$ & $6.10 \pm 2.6$ \\
\hline $\begin{array}{l}\text { Potential problems of } \\
\text { medication }^{d}\end{array}$ & $3.7 \pm 3.0$ & $3.25 \pm 2.9$ \\
\hline \multicolumn{3}{|l|}{$\begin{array}{l}\text { Satisfaction with consultation } \\
\text { duration }\end{array}$} \\
\hline Just right & $49.0(24)$ & $68.8(33)$ \\
\hline Too short & $42.9(21)$ & $31.3(15)$ \\
\hline Too long & $8.2(4)$ & $0(0)$ \\
\hline \multicolumn{3}{|l|}{ Additional sources of information ${ }^{a}$} \\
\hline Internet & $81.6(40)$ & $81.3(39)$ \\
\hline Package leaflet & $71.4(35)$ & $75.0(36)$ \\
\hline $\begin{array}{l}\text { Patient brochures/ } \\
\text { psychoeducation }\end{array}$ & $24.5(12)$ & $12.5(6)$ \\
\hline Family/friends & $10.2(5)$ & $12.5(6)$ \\
\hline
\end{tabular}


TABLE 1 | Continued

\begin{tabular}{lcc}
\hline & $\begin{array}{c}\text { Nocebo information } \\
\text { group }(\boldsymbol{n}=\mathbf{4 9 )} \\
\boldsymbol{M} \pm \boldsymbol{S} \boldsymbol{D} \text { or } \%(\boldsymbol{n})\end{array}$ & $\begin{array}{c}\text { Control group } \\
(\boldsymbol{n}=\mathbf{4 8})\end{array}$ \\
$\mathbf{M} \pm \mathbf{S D}$ or \% (n)
\end{tabular}

M, mean; SD, standard deviation; CES-D, Center for Epidemiological StudiesDepression scale.

${ }^{a}$ Multiple responses allowed.

${ }^{b}$ Other antidepressants include drugs mentioned $\leq 2$ times: Duloxetine, Clomipramine,

Paroxetine, and Quetiapine.

${ }^{c}$ Range 0-9.

${ }^{d}$ Range $0-8$.

of the manipulation check $(n=1)$. A total of 97 participants were included in the analyses, of which 49 and 48 were randomly allocated to the nocebo information group and to the control group, respectively.

Patients in both study groups were comparable with respect to socio-demographic characteristics (Table 1). When asked about their diagnosis, participants predominantly stated to receive antidepressants as treatment for depression (84.5\%) and/or anxiety disorders (42.3\%). More than $80 \%$ were still taking at least $80 \%$ of their medication; 10 participants have already discontinued antidepressant treatment. A majority received the medication information by their psychiatrist (54.6\%) and used the internet $(81.4 \%)$ or the package leaflet $(73.2 \%)$ as an additional information source. Pre-existing knowledge of the nocebo effect was assessed in the nocebo information group using an open question; three participants (6\%) could describe the effect correctly.

\section{Satisfaction With Information About Medication}

Figure 2 portrays the patients' satisfaction with the medication information received from the prescribing physicians; $59 \%$ of patients were overall satisfied, yet $41 \%$ were not. Information was judged inadequate to participate in shared decision-making about side effect-related treatments by over $40 \%$ (44\% not satisfied), and $41 \%$ felt inadequately informed to participate in shared decision-making about the antidepressant treatment (41\% not satisfied). Considering consultation time, 58.8, 4.1, and $37.1 \%$ viewed the duration to be "just right," "too long," and "too short," respectively.

Similarly, the SIMS indicated that patients were rather not satisfied with the obtained medication information. In comparison with the German norm population that consisted of $n=212$ chronically ill patients in the primary care system (hypertension, musculoskeletal diseases, diabetes type 2, cardiac insufficiency), our patient sample reported lower satisfaction (SIMS scores) for the total information received $[M=9.59, S D=$ $4.87 ; t_{(307)}=2.18, p=0.006$, Cohen's $d=0.34$ ], for the subscales action and usage of medication $\left[M=6.10, S D=2.59 ; t_{(307)}=\right.$
$2.19, p=0.029$, Cohen's $d=0.27]$, and for the potential problems of medication $\left[M=3.48, S D=2.91 ; t_{(307)}=2.83, p=0.006\right.$, Cohen's $d=0.34$.

\section{Informational Needs Disclosure About Side Effects}

Figure 3 shows that the control group more strongly desired to be informed about all side effects. Chi-square tests revealed significant group differences regarding all three items on side effect disclosure. The groups differed considering the perceived benefits of not being informed about all possible side effects $\left[X_{(4)}^{2}\right.$ $=14.88, p=0.005$, Cramer's $\mathrm{V}=0.39$ ], considering the desire to be thoroughly informed about possible side effects $\left[X_{(4)}^{2}=12.71\right.$, $p=0.013$, Cramer's $V=0.36]$, and considering the types of side effects they wish to be informed about $\left[X_{(3)}^{2}=8.86, p=0.031\right.$, Cramer's $\mathrm{V}=0.30]$.

\section{Disclosure About the Antidepressant's Modes of Actions}

A multivariate analysis of variance (MANOVA) revealed a significant multivariate effect of the study group on informational needs about the mechanisms of antidepressants [Wilks' $\lambda=$ $0.75, F_{(7,89)}=3.64, p=0.001$, partial $\eta^{2}=0.25$ ]. Except for information on "effects of antidepressants on neurotransmitters in the brain" (Figure 4), participants in the nocebo information group indicated an increased wish for information in all domains. $t$-Test for independent samples showed that the nocebo group desired more information about the pharmacological actions of antidepressants $\left[t_{(95)}=2.53, p=0.013\right.$, Cohen's $\left.d=0.52\right]$, about the non-pharmacological actions of antidepressants $\left[t_{(95)}=2.52\right.$, $p=0.013$, Cohen's $d=0.52$ ], on how expectations can influence the antidepressant's effectiveness $\left[t_{(95)}=2.05, p=0.043\right.$, Cohen's $d=0.42$ ], on how not believing in the antidepressant's benefits can make it less effective $\left[t_{(88.07)}, p<0.001\right.$, Cohen's $d=$ 0.83 ], on how time itself can ease suffering $\left[t_{(95)}=3.02, p=\right.$ 0.003 , Cohen's $d=0.61$, and about how side effect can develop due to heightened bodily attention $\left[t_{(95)}=2.98, p=0.004\right.$, Cohen's $d=0.61$.

\section{DISCUSSION}

This study showed that patients, who have learned about the nocebo effect, are more open to contextualized information about their antidepressant medication. Patients with an indication for antidepressant treatment, in general, wish to be informed about the effects and potential side effects of their antidepressant medication. However, the group who has received information about the nocebo effect-in comparison with the group who did not receive that information-indicated that withholding the potential side effects and a less thorough disclosure of side effects would be beneficial. They also wished for a more personalized approach, i.e., $41 \%$ of participants wished to only be informed about personally relevant side effects (vs. $29 \%$ of participants in the control group).

Patients in the nocebo information group also reported an increased wish to be informed about the antidepressants' 


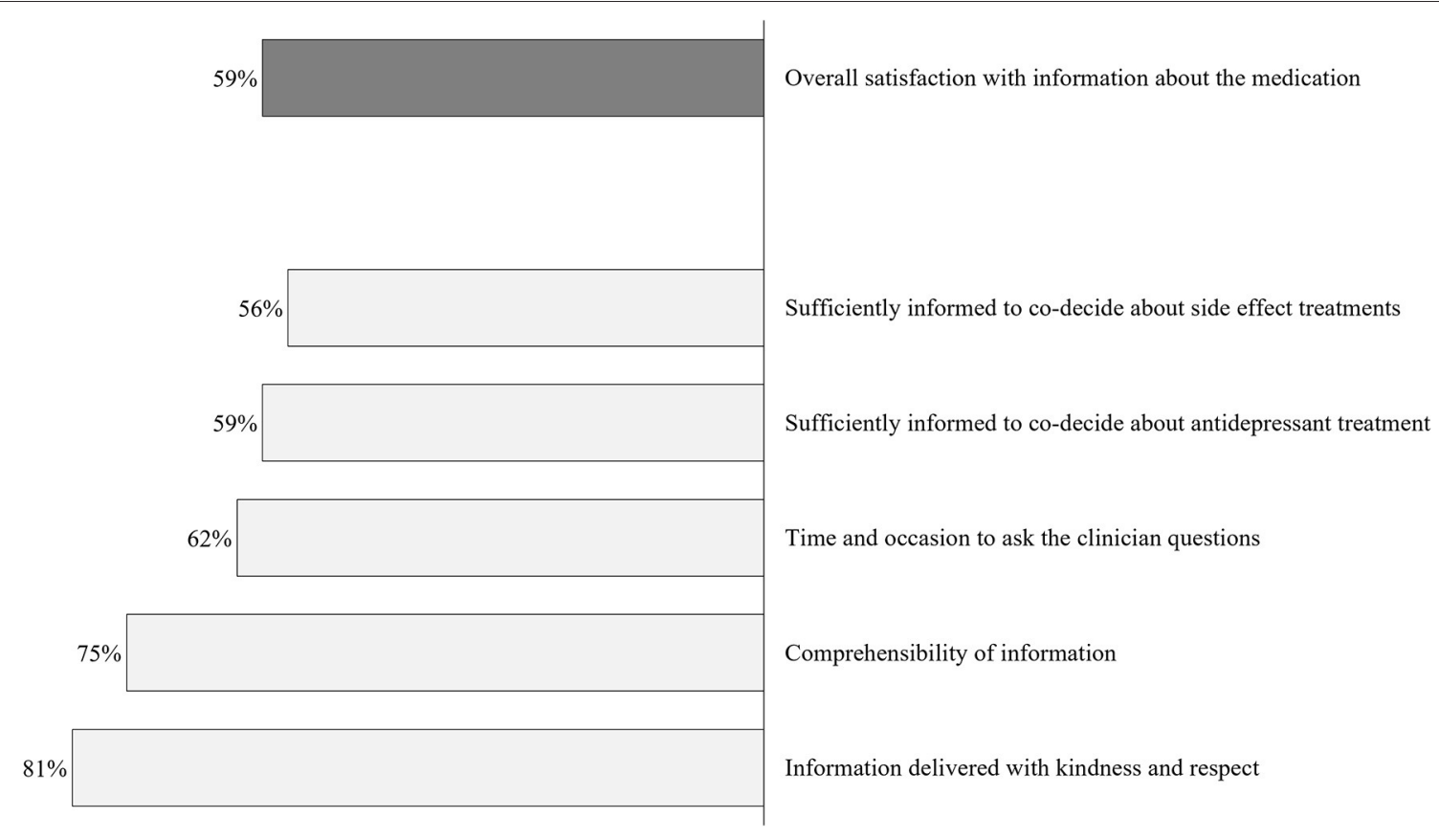

FIGURE 2 | Satisfaction with information about medication at prescription. Percentages indicate the proportion of patients agreeing to each item (scores \#3-5) $(N=97)$.

A

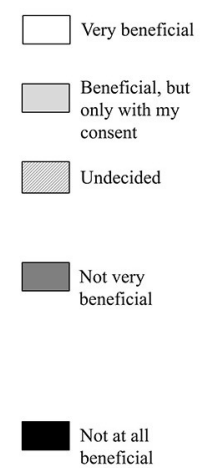

beneficial

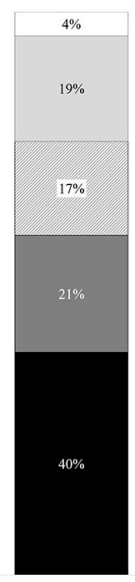

Control $(n=48)$ Nocebo Info $(n=49)$
B

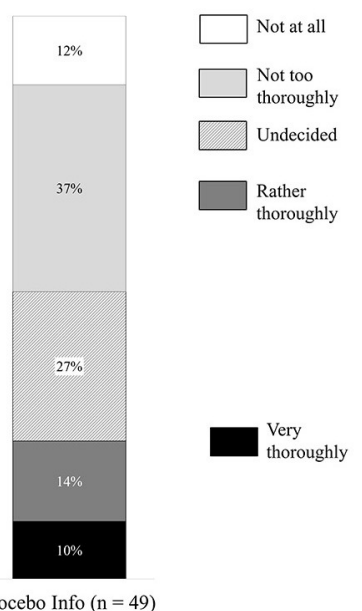

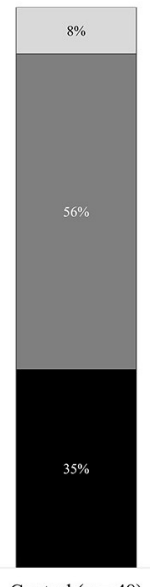

Control $(n=48) \quad$ Nocebo Info $(n=49)$
C

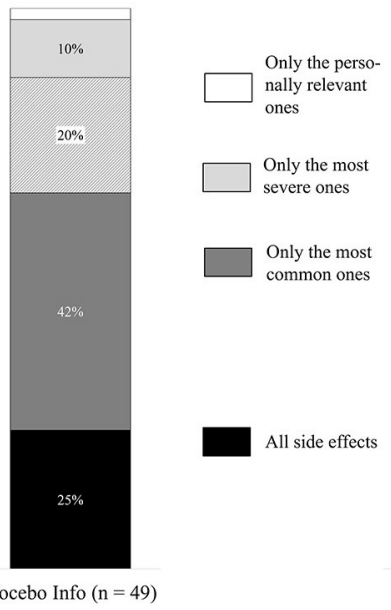

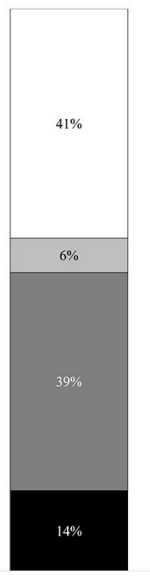

Control $(n=48) \quad$ Nocebo Info $(n=49)$

FIGURE 3 | Preferred information disclosure about side effects. Black marked columns indicate the percentage of participants who wish to receive detailed information about the potential side effects. (A) Would you find it beneficial if your practitioner did not inform you about all possible side effects? (B) How thoroughly would you like your practitioner to inform you about possible side-effects? (C) Which side would you like to be informed about.

mode of action, which includes pharmacological and nonpharmacological treatment mechanisms. This suggests that, once aware that psychological factors can contribute to side effects, participants were more receptive to information considering the medication's non-pharmacological mechanisms. Especially for antidepressants, for which placebo effects determine up to $75 \%$ of the effectiveness $(8-10,36)$, nonspecific factors, such as expectations and positive beliefs, may influence treatment outcomes. Knowing about the nocebo effects provides the groundwork for learning more about non-pharmacological 


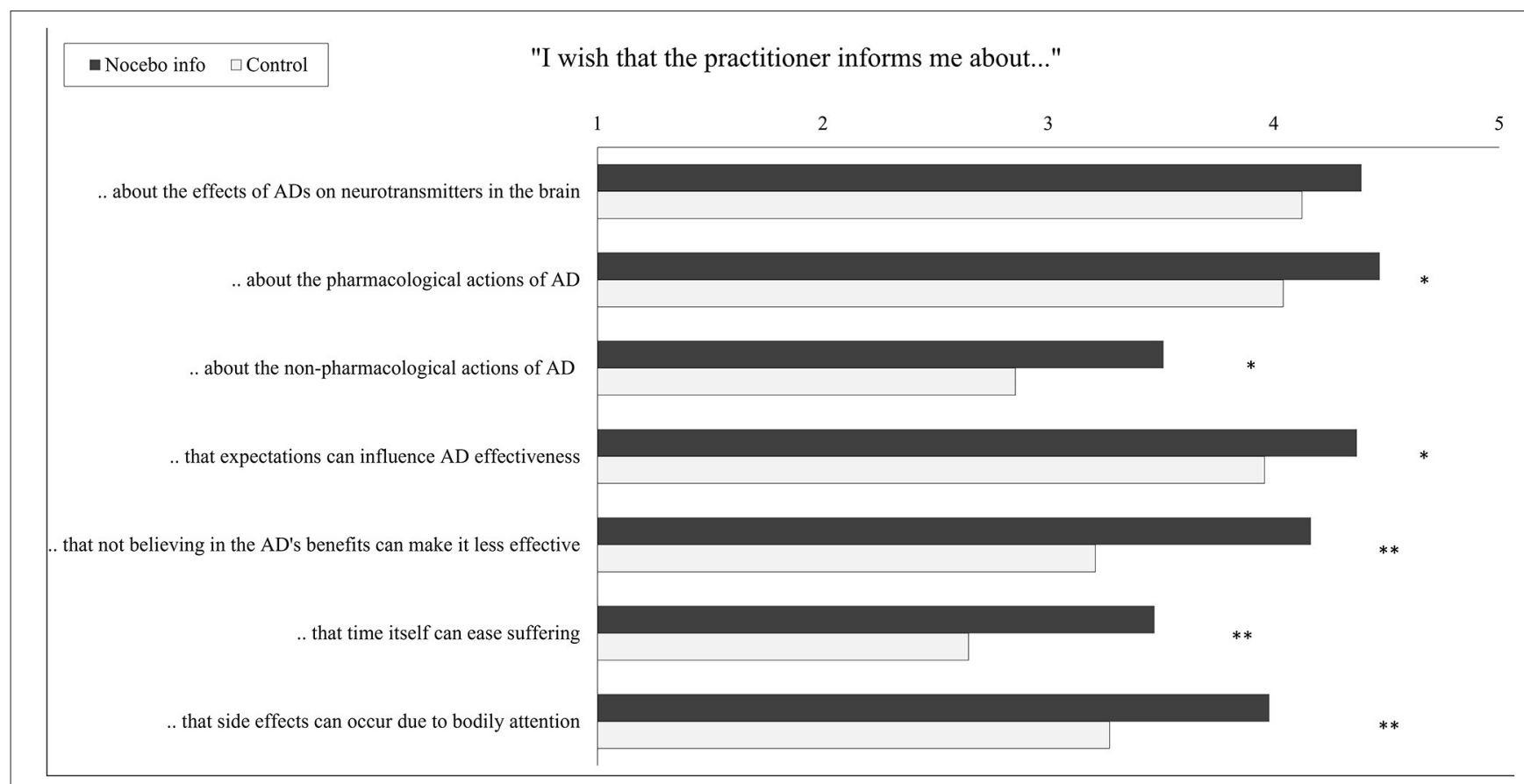

FIGURE 4 | Wish for disclosure about modes of action of the antidepressant by the intervention group. Student's $t$-tests for independent samples were conducted. Each scale ranges from 1 "do not agree at all" to 5 "fully agree"; bars indicate means. AD, antidepressant, ${ }^{*} p<0.05,{ }^{\star *} p<0.01$.

treatment mechanisms, which again, might positively affect treatment efficacy.

When asked about their overall satisfaction with the medication information they received at prescription, only $59 \%$ of the $n=97$ participants indicated overall satisfaction. For most participants, the information was delivered with kindness and respect (81\%) and was well comprehensible (75\%). However, in view of "time and occasion for questions to the clinician," fewer participants were satisfied (62\%). Notably, many participants did not feel adequately informed to make decisions considering managing the potential side effects and their antidepressant treatment (satisfaction rates: 59 and $56 \%)$. In addition, the consultation time at prescription was evaluated as "too short" in $37 \%$ of all cases. These results can be interpreted as compatible with the current public health crisis of long-term antidepressant intake. About 14\% of antidepressant users report an intake duration of 10 years (37), although there is no evidence for increased benefits for long-term intake $(38,39)$. On the other hand, many patients discontinue their medication without consulting their practitioner (40), which can result in heightened recurrence risk and burdening symptoms. Providing patients with more information at prescription might be an essential component of preventing abrupt discontinuation or the "better safe than sorry"-motivated long-term intake.

Up to $57 \%$ of patients experience nocebo effects from antidepressants $(8,41)$. Symptoms include dry mouth, fatigue, drowsiness, constipation, sexual problems, and vision/accommodation problems. Since all types of side effects seemed equally amendable to nocebo (8), it can be assumed that side effects from antidepressants in general might be influenced in terms of their incidence and intensity by patients' negative expectations. Furthermore, $40 \%$ of the patients in the placebo groups of clinical trials discontinue antidepressant treatment because of intolerable side effects $(8,10)$. Taken together, nocebo effects from antidepressant treatment constitute a serious clinical problem affecting patients' well-being as well as medication adherence. Clinical ways of tackling this problem, for example, through optimized informed consent procedures, thus seem promising not only for the benefit of the patient but also for the benefit of the healthcare systems struggling with costs from increased long-term antidepressant intake and self-directed discontinuation.

While there have been suggestions to inform patients about the nocebo effect (42), to the best of our knowledge, this study is the first to assess the patients' wish for information after learning about the nocebo effect. A previous study showed that explaining the nocebo effect reduces symptomatic experiences in people reporting symptoms attributed to windfarm generated infrasound, supporting the potential positive impact of providing improved information about nocebo effects (43). Further strengths include the use of a control condition and the standardized presentation of the information, which could be easily implemented into medication package leaflets. 


\section{LIMITATIONS}

While the study's online format minimized context effects and bias toward investigators, it does not provide opportunities for questions to a clinician, which could have enhanced the understanding of the nocebo effect. Clinically more valid routes to provide disclosure to patients about the nocebo effect include semi-structured individual consultations (31) or might be offered via shared clinical notes. Sharing clinical notes with patients via digitally accessible records, a practice that is becoming increasingly common in northern European countries and worldwide, might provide the opportunity to directly augment expectation effects (44). However, the ability to do this depends on the clinicians' knowledge about the influence of expectations on treatment efficacy and tolerability (24). The claim to promote nocebo literacy by addressing expectation effects in clinical education has been recently raised in a consensus paper (45).

The sample size with 97 participating patients was rather small. Among other benefits, such as increased power, larger samples with an increased chance of including patient with diverse interests in expectation or nocebo effects might help to control for a potential responder bias, since interest in and experiences with these effects might influence patient's informational needs. However, the study was promoted as a survey on experiences with antidepressants, which should have reduced a bias toward selective interests in the topic. All measures within this study were patient self-reports. Future studies should aim to include objective measures, such as pill counts as measures of adherence. Furthermore, the focus of this study was on patients taking antidepressants; thus, conclusions on other samples need to be drawn with caution. Since participants were not scheduled to receive a new prescription and had to answer hypothetically, future research should examine the information needs where the outcome actually determines the information of new medication given by a doctor.

Our study did not explore whether patients who are informed about the nocebo effect and prefer to receive fewer side effect information within their doctors' consultation actually change their behavior in terms of decreased searching for negative information online and in their conversations with fellow patients. Thus, the potential of adapted informed consent procedures, such as authorized concealment, to really prevent nocebo effects should be investigated in further studies (46). Importantly, these future studies might also consider the potential risks and downsides of authorized concealment, such as increased anxiety or overlooking and downplaying of potentially serious adverse events due to their attribution to the nocebo effect (5). Moreover, physicians should not misinterpret a preference for lesser side effect information as a justification for providing less information about side effects in general. Conclusions from this scientific debate should always emphasize that patent autonomy, as one of the fundamental principles of informed consent, and in this case of authorized concealment, should remain intact.

\section{CONCLUSIONS}

To our knowledge, our study is the first to investigate patients' views of the potential contextualized informed consent procedures. In contrast to experts' suggestions of withholding certain side effect information, most patients wish to receive information about all possible side effects. Only when patients have been informed about the nocebo effect, they agreed to receive adjusted medical information. Hence, patients should be informed about the underlying rationale of preventing nocebo effects before informed consent is contextualized. Future studies should investigate whether contextualized informed consent can optimize expectations as shown by Heisig et al. (28) and, furthermore, reduce side effect burden and improve the efficacy of medications.

Clinicians should be aware of the nocebo effect and provide information to the patient accordingly. This study shows that knowing about the nocebo effect can alter the need for information, which should be considered to achieve a truly informed consent and ensure patients' autonomy.

\section{DATA AVAILABILITY STATEMENT}

The raw data supporting the conclusions of this article will be made available by the authors, without undue reservation.

\section{ETHICS STATEMENT}

The studies involving human participants were reviewed and approved by Psychotherapy Chamber Hamburg, Germany. The patients/participants provided their written informed consent to participate in this study.

\section{AUTHOR CONTRIBUTIONS}

YN and MS-M initiated the study design. TK, EW, and MS-M conducted the study. TK, EW, YP, YN, and MS-M analyzed and interpreted the data. YN, YP, and TK drafted the manuscript. All authors made refinements and approved the final manuscript.

\section{FUNDING}

This study was supported by funds from the German Research Foundation (Deutsche Forschungsgemeinschaft, DFG), CRC 289 Treatment Expectation, Project Number 422744262.

\section{ACKNOWLEDGMENTS}

We thank Myriel Bahnsen, Angelo Urso, and Juliane Meise for their support in conducting the study, Sarah Gast for her help with editing the manuscript, and the two reviewers for their insightful suggestions to improve the quality of the paper. 


\section{REFERENCES}

1. Colloca L, Finniss D. Nocebo effects, patient-clinician communication, and therapeutic outcomes. JAMA. (2012) 307:567-8. doi: 10.1001/jama.2012.115

2. Faasse K, Petrie KJ. The nocebo effect: patient expectations and medication side effects. Postgrad Med J. (2013) 89:540-6. doi: 10.1136/postgradmedj-2012-131730

3. Mondaini N, Gontero P, Giubilei G, Lombardi G, Cai T, Gavazzi A, et al. Finasteride $5 \mathrm{mg}$ and sexual side effects: how many of these are related to a nocebo phenomenon? J Sex Med. (2007) 4:1708-12. doi: 10.1111/j.1743-6109.2007.00563.x

4. Faasse K, Huynh A, Pearson S, Geers A., Helfer SG, Colagiuri B. The influence of side effect information framing on nocebo effects. Ann Behav Med. (2019) 53:621-9. doi: 10.1093/abm/kay071

5. Alfano M. Placebo effects and informed consent. Am J Bioethics. (2015) 15:3-12. doi: 10.1080/15265161.2015.1074302

6. Mahr A, Golmard C, Pham E, Iordache L, Deville L, Faure P. Types, frequencies, and burden of nonspecific adverse events of drugs: analysis of randomized placebo-controlled clinical trials. Pharmacoepidem Drug Saf. (2017) 26:731-41. doi: 10.1002/pds.4169

7. Mitsikostas DD, Mantonakis L, Chalarakis N. Nocebo in clinical trials for depression: a meta-analysis. Psychiatry Res. (2014) 215:82-6. doi: 10.1016/j.psychres.2013.10.019

8. Rief W, Nestoriuc Y, von Lilienfeld-Toal A, Dogan I, Schreiber F, Hofmann SG, et al. Differences in adverse effect reporting in placebo groups in SSRI and tricyclic antidepressant trials. Drug Saf. (2009) 32:1041-56. doi: 10.2165/11316580-000000000-00000

9. Rief W, Nestoriuc Y, Weiss S, Welzel E, Barsky AJ, Hofmann SG. Metaanalysis of the placebo response in antidepressant trials. J Affective Dis. (2009) 118:1-8. doi: 10.1016/j.jad.2009.01.029

10. Shedden-Mora M, Nestoriuc Y, Rief W. Lessons learned from placebo groups in antidepressant trials. Philos Trans R Soc B. (2011) 366:1879-88. doi: 10.1098/rstb.2010.0394

11. Zilcha-Mano S, Brown PJ, Roose SP, Cappetta K, Rutherford BR. Optimizing patient expectancy in the pharmacologic treatment of major depressive disorder. Psychol Med. (2019) 9:2414-20. doi: 10.1017/S0033291718003343

12. Bingel U. Avoiding nocebo effects to optimize treatment outcome. JAMA. (2014) 312:693-4. doi: 10.1001/jama.2014.8342

13. Nestoriuc Y, Orav JE, Liang MH, Horne R, Barsky AJ. Prediction of nonspecific side effects in rheumatoid arthritis patients by beliefs about medicines. Arthritis Care Res. (2010) 62:791-9. doi: 10.1002/acr.20160

14. Colagiuri B, McGuinness K, Boakes RA, Butow PN. Warning about side effects can increase their occurrence: an experimental model using placebo treatment for sleep difficulty. J Psychopharmacol. (2012) 26:1540-7. doi: $10.1177 / 0269881112458730$

15. Petrie KJ, Moss-Morris R, Grey C, Shaw M. The relationship of negative affect and perceived sensitivity to symptom reporting following vaccination. $\mathrm{Br} J$ Health Psychol. (2004) 9:101-11. doi: 10.1348/135910704322778759

16. Horne R, Chapman SC, Parham R, Freemantle N, Forbes A, Cooper V. Understanding patients' adherence-related beliefs about medicines prescribed for long-term conditions: a meta-analytic review of the necessity-concerns framework. PLoS ONE. (2013) 8:e80633. doi: 10.1371/journal.pone.0080633

17. Barsky AJ, Saintfort R, Rogers MP, Borus JF. Nonspecific medication side effects and the nocebo phenomenon. JAMA. (2002) 287:622-7. doi: 10.1001/jama.287.5.622

18. Vögtle E, Barke A, Kröner-Herwig B. Nocebo hyperalgesia induced by social observational learning. Pain. (2013) 154:1427-33. doi: 10.1016/j.pain.2013.04.041

19. Häuser W, Hansen E, Enck P. Nocebo phenomena in medicine: their relevance in everyday clinical practice. Dtsch Arztebl Int. (2012) 109:459-65. doi: 10.3238/arztebl.2012.0459

20. Kube T, Rief W. Why dysfunctional expectations in depression persistresults from two experimental studies investigating cognitive immunization. Psychol Med. (2018) 49:1532-44. doi: 10.1017/S0033291718002106

21. Maund E, Dewar-Haggart R, Williams S, Bowers H, Geraghty AW, Leydon $\mathrm{G}$, et al. Barriers and facilitators to discontinuing antidepressant use: a systematic review and thematic synthesis. J Affect Disord. (2019) 245:38-62. doi: 10.1016/j.jad.2018.10.107
22. Lohse MJ, Seifert R. Psychopharmaka. In: Schwabe U, Paffrath D, Ludwig WD, Klauber J, editors. Arzneiverordnungs-Report. Berlin: Springer (2019).

23. Pratt LA, Brody DJ, Gu Q. Antidepressant Use Among Persons Aged 12 and Over: United States, 2011-2014. NCHS Data Brief, no 283. Hyattsville, MD: National Center for Health Statistics (2017).

24. Kampermann L, Nestoriuc Y, Shedden-Mora MC. Physicians' beliefs about placebo and nocebo effects in antidepressants-an online survey among German practitioners. PLoS ONE. (2017) 12:e0178719. doi: 10.1371/journal.pone.0178719

25. Colloca L, Miller FG. The nocebo effect and its relevance for clinical practice. Psychosom Med. (2011) 73:598-603. doi: 10.1097/PSY.0b013e3182294a50

26. Barnes K, Faasse K, Geers AL, Helfer SG, Sharpe L, Colloca L, Colagiuri B. Can positive framing reduce nocebo side effects? Current evidence and recommendation for future research. Front Pharmacol. (2019) 10:167. doi: 10.3389/fphar.2019.00167

27. De las Cuevas C, Peñate W, Sanz EJ. Risk factors for non-adherence to antidepressant treatment in patients with mood disorders. Eur J Clin Pharmacol. (2014) 70:89-98. doi: 10.1007/s00228-013-1582-9

28. Heisig SR, Shedden-Mora MC, Hidalgo P, Nestoriuc Y. Framing and personalizing informed consent to prevent negative expectations: an experimental pilot study. Health Psychol. (2015) 34:1033-7. doi: $10.1037 /$ hea0000217

29. Pan Y, Kinitz T, Stapic M, Nestoriuc Y. Minimizing drug adverse events by informing about the nocebo effect-an experimental study. Front Psychiat. (2019) 10:504. doi: 10.3389/fpsyt.2019.00504

30. Wells RE, Kaptchuk TJ. To tell the truth, the whole truth, may do patients harm: the problem of the nocebo effect for informed consent. Am J Bioethics. (2012) 12:22-9. doi: 10.1080/15265161.2011.652798

31. Quidde J, Pan Y, Salm M, Hendi A, Nilsson S, Oechsle K, et al. Preventing adverse events of chemotherapy by educating patients about the nocebo effect (RENNO study) - study protocol of a randomized controlled trial with gastrointestinal cancer patients. BMC Cancer. (2018) 18:1-8. doi: 10.1186/s12885-018-4814-7

32. Lehr D, Hillert A, Schmitz E, Sosnowsky N. Screening depressiver Störungen mittels Allgemeiner Depressions-Skala (ADS-K) und State-Trait Depressions Scales (STDS-T). Eine vergleichende Evaluation von Cut-Off-Werten. Diagnostica. (2008) 54:61-70. doi: 10.1026/0012-1924.54.2.61

33. Radloff LS. The CES-D scale: a self-report depression scale for research in the general population. Appl Psychol Meas. (1977) 1:385-401. doi: 10.1177/014662167700100306

34. Ziller V, Kalder M, Albert U-S, Holzhauer W, Ziller M, Wagner U, et al. Adherence to adjuvant endocrine therapy in postmenopausal women with breast cancer. Ann Oncol. (2009) 20:431-6. doi: 10.1093/annonc/mdn646

35. Horne R, Hankins M, Jenkins R. The satisfaction with information about medicines scale (SIMS): a new measurement tool for audit and research. BMJ Qual Saf. (2001) 10:135-40. doi: 10.1136/qhc.0100135

36. Meister R, Abbas M, Antel J, Peters T, Pan Y, Bingel U, et al. Placebo response rates and potential modifiers in double-blind randomized controlled trials of second and newer generation antidepressants for major depressive disorder in children and adolescents: a systematic review and meta-regression analysis. Eur Child Adolesc Psychiatry. (2020) 29:253-73. doi: 10.1007/s00787-018-1244-7

37. Pratt LA, Brody DJ, Gu Q. Antidepressant Use in Persons Aged 12 and Over: United States, 2005-2008. NCHS Data Brief, no 76. Hyattsville, MD: National Center for Health Statistics (2011).

38. Bauer M, Severus E, Koehler S, Whybrow PC, Angst J, Moeller H-J. World Federation of Societies of Biological Psychiatry (WFSBP) guidelines for biological treatment of unipolar depressive disorders. Part 2: Maintenance treatment of major depressive disorder-update 2015. World J Biol Psychiatry. (2015) 16:76-95. doi: 10.3109/15622975.2014.1001786

39. Hughes S, Cohen D. A systematic review of long-term studies of drug treated and non-drug treated depression. J Affect Disord. (2009) 118:9-18. doi: 10.1016/j.jad.2009.01.027

40. Samples H, Mojtabai R. Antidepressant self-discontinuation: results from the collaborative psychiatric epidemiology surveys. Psychiatr Serv. (2015) 66:455-62. doi: 10.1176/appi.ps.201400021

41. Howick J, Webster R, Kirby N, Hood K. Rapid overview of systematic reviews of nocebo effects reported by patients taking placebos 
in clinical trials. Trials. (2018) 19:1-8. doi: 10.1186/s13063-0183042-4

42. Weissenfeld J, Stock S, Lüngen M, Gerber A. The nocebo effect: a reason for patients' non-adherence to generic substitution? Die Pharm An Int J Pharm Sci. (2010) 65:451-6. doi: 10.1691/ph.2010.9749

43. Crichton F, Petrie KJ. Health complaints and wind turbines: the efficacy of explaining the nocebo response to reduce symptom reporting. Environ Res. (2015) 140:449-55. doi: 10.1016/j.envres.2015.04.016

44. Blease CR, Delbanco T, Torous J, Ponten M, DesRoches CM, Hagglund $\mathrm{M}$, et al. Sharing clinical notes, and placebo and nocebo effects: can documentation affect patient health? J Health Psychol. (2020). doi: 10.1177/1359105320948588. [Epub ahead of print].

45. Evers AW, Colloca L, Blease C, Annoni M, Atlas LY, Benedetti $\mathrm{F}$, et al. Implications of placebo and nocebo effects for clinical practice: expert consensus. Psychother Psychosomat. (2018) 87:204-10. doi: $10.1159 / 000490354$
46. Blease C. Authorized concealment and authorized deception: well-intended secrets are likely to induce nocebo effects. Am $J$ Bioethics. (2015) 15:23-5. doi: 10.1080/15265161.2015.10
74310

Conflict of Interest: The authors declare that the research was conducted in the absence of any commercial or financial relationships that could be construed as a potential conflict of interest.

Copyright (C) 2021 Nestoriuc, Pan, Kinitz, Weik and Shedden-Mora. This is an openaccess article distributed under the terms of the Creative Commons Attribution License (CC BY). The use, distribution or reproduction in other forums is permitted, provided the original author(s) and the copyright owner(s) are credited and that the original publication in this journal is cited, in accordance with accepted academic practice. No use, distribution or reproduction is permitted which does not comply with these terms. 